\title{
Ginga com tapioca: gastronomia do mercado da Redinha como atrativo turístico
}

\section{Ginga with tapioca: Redinhas market gastronomy as tourism attraction}

\section{Charllys Lima}

Bacharel em Turismo pela Universidade Federal do Rio Grande do Norte-UFRN, Natal/RN, Brasil

E-mail: charllys7@hotmail.com

\section{Sueli Moreira}

Professor do Departamento de Turismo da Universidade Federal do Rio Grande do NorteUFRN, Natal/RN, Brasil

E-mail: suelimoreira@yahoo.com.br

\section{Alicia Cabral}

Professora do Instituto Federal de Educação, Ciência e Tecnologia do Rio Grande do Norte/IFRN

E-mail: aliciacabral27@gmail.com

\section{Caroline Silva}

Graduanda em Turismo pela Universidade Federal do Rio Grande do Norte-UFRN, Natal/RN, Brasil

E-mail: anacosta_caroline@hotmail.com

\section{Maria Luiza Mesquita}

Especialista em Gastronomia pela Royal Prestige Sistema de Cozinha. Natal/RN E-mail: mesquitaluizama@gmail.com 


\section{RESUMO}

O presente estudo tem como objetivo analisar o Mercado da Redinha enquanto potencial turístico gastronômico, através da comercialização da ginga com tapioca, um prato típico da cidade de Natal. Apesar de também ser comercializado por vendedores ambulantes nas principais praias do litoral natalense, o Mercado Público da Redinha é o ponto original onde se comercializa esse prato. Muitos turistas que visitam a capital potiguar desejam conhecer a gastronomia típica, mas o mercado atrai especialmente turistas locais e moradores como opção de entretenimento. Realizou-se um estudo de natureza quantitativa descritiva, cujos dados foram obtidos através de formulário composto por 15 questões respondidas por 31 usuários do Mercado. Para análise, as questões foram organizadas em categorias que abrangeram o perfil dos usuários e suas opiniões em relação à infraestrutura do mercado, à frequência de visitação, meio de divulgação que os levou a conhecer o Mercado, percepção sobre qualidade de acesso e demandas de melhorias. Em relação à gastronomia, indagou-se sobre o cardápio servido, o gosto e apresentação do prato, o valor cobrado e a opinião sobre a qualidade do atendimento. Os resultados evidenciaram pontos negativos como a falta de saneamento adequado e regular que também comprometia a higiene; bem como a falta de infraestrutura como principal reclamação entre os entrevistados. Em relação aos pontos positivos foram incluídos: preço justo, bom atendimento e gosto agradável do prato. A maioria dos entrevistados indicaria o mercado a outros e, apesar dos diversos problemas apontados, os usuários, especialmente, do sexo masculino, são atraídos em busca da ginga com tapioca para beber com amigos na semana. A revisão da dinâmica interna do Mercado pode fomentar como estratégia para incluí-lo no roteiro do turismo gastronômico regional.

Palavras-Chave: Turismo Cultural, Mercado da Redinha, Natal-RN, Gastronomia Regional.

\section{ABSTRACT}

This study is an analysis of the potential for gastronomic tourism at the Redinha Public Market (Mercado Público da Redinha) in Natal, RN, Brazil that emphasizes the commercial marketability of a local speciality. The dish, called ginga com tapioca, is entirely unique to Natal. The Ginga (anchoviella lepidentostole) with tapioca is a type of sandwich with local ingredients. Although this dish is also sold by street vendors along the beaches of the Natal coast, the Redinha Public Market is the main vendor of this type of regional cuisine. Many foreign tourists visiting the Natal would like to experience the traditional cuisine of the region, yet at present the market mainly attracts domestic tourists and serves as an entertainment option for local residents. The descriptive study is based on quantitative data obtained through semi-structured survey with 15 questions; the survey was used to interview 31 visitors to the market. For data analysis, the questions were divided into categories covering the visitors profile data and gauging their opinions on: market infrastructure, how often they visit, where they learned about the market, and their perception of the quality of the food and services, and potential improvements. Regarding the food, we solicited information concerning the type of local items served on the menu, the taste and presentation of the dish, the amount charged and the quality of the services provided. The results demonstrate weaknesses that inhibit the market growth as a sector for tourism. The main concern of respondents was the lack of adequate and regular sanitation and potentially compromised hygiene; the lack of adequate infrastructure and the demand for higher quality services to access the market. The results also demonstrate that the perception of customers is that ginga com tapica is served at a fair price, with good customer service and the majority enjoyed the 
taste and flavour of the dish. We conclude that the majority of respondents would recommend the public market to other people and, despite the problems we identified, customers, in particular male customers, felt that ginga com tapioca was an entirely unique local option as a leisure time snack for drinking and socializing and that it has the potential to be useful to a strategy of regional gastronomic tourism.

Keywords: Cultural Tourism, Mercado da Redinha, Regional Cuisine, Gastronomy.

\section{INTRODUÇÃO}

A gastronomia revela um dos mais importantes traços da identidade cultural de um povo ou região. De acordo com Schluter (2003), a apreciação da gastronomia se destaca cada vez mais nas atividades turísticas. Mais do que um ato de se alimentar, a gastronomia enquanto atrativo turístico pode trazer benefícios econômicos, sociais e culturais. A gastronomia pode ser motivada pelo interesse dos turistas em conhecer as raízes da culinária e entender a cultura da região visitada. Peccini (2013, p.207) acrescenta que, por diversas vezes, a gastronomia é "colocada no centro das discussões do turismo como um dos pontos de referência para festas, nas quais se coloca como atrativo e como tema, ou como parte da arte de bem receber os visitantes."

Sob contexto que considera a gastronomia enquanto produto e serviço estruturantes para a atividade turística e o papel da gastronomia regional enquanto estratégia para fortalecer a identidade cultural local no enfrentamento do processo de globalização, elaborou-se o presente estudo com o objetivo de analisar o Mercado Público da Redinha, localizado próximo à capital potiguar, enquanto potencial turístico devido à invenção única do prato ginga com tapioca cujo preparo segue sendo realizado, de modo artesanal, no próprio local, onde se dá o consumo.

O Mercado Público foi fundado em 1949 às margens do Rio Potengi, no Bairro da Redinha que fica a $2 \mathrm{~km}$ do centro de Natal-RN, na zona norte da capital potiguar. Tem seu limite ao norte com o município de Extremoz, ao sul com as salinas, ao leste com o Oceano Atlântico e o Rio Potengi e a oeste com os bairros do Potengi e Pajuçara. O Bairro da Redinha inicialmente era uma colônia de pescadores e o nome Redinha é de origem lusitana proveniente do nome de uma vila de Portugal. O Mercado é um prédio de estrutura simples e antiga onde se comercializam peixes crus, assim como petiscos de peixe prontos para o consumo, e a tradicional ginga com tapioca.

A ginga (anchoviella lepidentostole), é um peixe miúdo que, depois de salgado, é espetado em palito de coqueiro, é empanado em farinha de mandioca e frito no óleo de dendê. 
A tapioca é feita da goma de mandioca processada que, após ser peneirada, acrescenta-se o sal e o coco ralado, é levada ao fogo e aquecida sobre uma frigideira. Depois de pronta, recebe o espeto de ginga frita - Secretaria Municipal do Meio Ambiente e Urbanismo [SEMURB] (, 2005) como recheio, e assim se obtém o tradicional prato ginga com tapioca. Trata-se, portanto, de um tipo de gastronomia original, que motiva a frequência aos mercados, tornando-os encantadores pelas raízes históricas e culturais de um povo.

É possível afirmar que a criação do prato deu-se pela complementaridade da pesca, atividade masculina, ao manuseio artesanal, prática feminina. A complementaridade entre gêneros foi amplamente investigada no litoral potiguar por Woortmann (1992, p.41):

A classificação do espaço natural é também uma classificação de espaços sociais e de domínios pertinentes a cada gênero. Num plano mais geral, dado pelo primeiro discurso oferecido ao observador, o espaço é classificado de maneira bipolar: o mar é percebido como domínio do homem, em oposição a terra, domínio da mulher.

Ainda de acordo com R. F. Dantas, Medeiros, Damasceno, e A.G.A. Dantas (2014), a origem da ginga com tapioca se deu entre as décadas de 50 e 60, quando Geraldo Januário, pescador da Praia da Redinha, observou a quantidade de gingas, também chamadas de manjubinhas, que eram descartadas e desperdiçadas na praia pelo fato de ser um peixe muito miúdo e sem valor comercial. O pescador decidiu recolher essas gingas e levá-las para casa e em complemento ao seu trabalho de pesca, entrou o trabalho de Dona Dalila, sua esposa, que se dedicou a limpar, salgar e colocar em palitos feitos das hastes das folhas de coqueiro; e conta a tradição oral que "enquanto sua esposa fritava a ginga, fazia a tapioca". O trabalho dela tem tido continuidade, não só por sua filha, Ivanize Januário, também sucessora, que ainda trabalha em um dos boxes do mercado público, como também por comerciantes dos demais boxes do mercado.

A ginga com tapioca é mais que uma receita doméstica, é uma receita de família potiguar que ganhou o Brasil, registra Dantas (2015); vendedores ambulantes comercializam esse petisco pelas praias de Natal, preservando e dando continuidade à memória desse quitute que se tornou patrimônio cultural gastronômico de Natal, por ser típico e de tradição:

tradição gastronômica é um saber-fazer transmitido entre gerações e cujos significados, dentro da própria lógica da dinâmica cultural, podem ser alterados ou adaptados, sem que sejam perdidas, no entanto, determinadas características e conteúdos que garantam seu reconhecimento (Gimenes, 2009, p. 19). 
A ginga com tapioca é um verdadeiro "sanduiche de marinheiro", conforme prefaciou Medeiros (2015) como citado em Dantas (2015) que pode ser consumido fora das praias. A ginga com tapioca faz do Mercado Público da Redinha um ponto tradicional de visitação único no mundo. Em respeito a esse contexto histórico, optou-se pela realização do presente estudo junto ao Mercado Público da Redinha, na praia da zona norte de Natal, onde o prato típico mais famoso de Natal surgiu e ainda hoje é comercializado.

Mercados Públicos são muito importantes na cidade como atrativos turísticos. Várias cidades utilizam esses espaços para desenvolver ou impulsionar o seu turismo. Esses espaços complementam a oferta de atrativos culturais, atraindo público jovem e familiar. Opções culturais regionais beneficiam a atividade turística e repercute na economia local.

\section{REFERENCIAL TEÓRICO}

\subsection{TURISMO CULTURAL}

O turismo na atualidade é considerado a principal atividade econômica, sendo mais importante que outros setores da economia (Dias \& Aguiar, 2002). Dessa forma, torna-se um grande gerador de empregos e renda pelo fato de prestar serviços como a hospedagem, meios de transportes e alimentação, possibilitando assim a contratação de mais pessoas. Há várias definições para o termo turismo e, de acordo com De La Torre (1992, como citado em Barreto, 2003, p.13):

O turismo é um fenômeno social que consiste no deslocamento voluntário e temporário de indivíduos ou grupos de pessoas que, fundamentalmente por motivos de recreação, descanso, cultura ou saúde, saem do seu local de residência habitual para outro, no qual não exercem nenhuma atividade lucrativa nem remunerada, gerando múltiplas inter-relações de importância social, econômica e cultural.

O turismo remete à ideia de deslocamento de pessoas e interação com expressões culturais distintas daquelas de seu território. A linguagem e a culinária são as principais expressões da identidade da cultura de um povo. Para Lévi-Strauss, (2006, p.448), a culinária de uma sociedade traduz a estrutura e revela suas contradições. Portanto, comunicação e a alimentação são experiências sócio-vitais fundamentais para garantir a interação cultural.

Qualquer que seja o motivo da viagem haverá sempre um elemento cultural a ser consumido dentre toda a produção associada ao turismo: a gastronomia, a arte, o artesanato ou outros produtos locais, as paisagens naturais e 
culturais do receptivo, suas festas e celebrações, a música ao vivo nos bares e a cultura viva presente nas ruas" (Myanaki , Leite, Cesar, \& Stigliano 2007, p.19).

Com a expansão do turismo e o aumento do interesse dos turistas em conhecer outras culturas, dar-se a necessidade de segmentar o turismo como forma de captar esse nicho específico e assim tentar oferecer um serviço de qualidade a um grupo específico. Quando esse interesse visa à cultura de um local denomina-se "turismo cultural", e consiste em trabalhar com os aspectos sociais e históricos que caracterizam uma determinada localidade, entre eles: hábitos, costumes, gastronomia, manifestações populares, arquitetura, edificações, artesanatos, entre outros (Panosso Netto \& Ansarah, 2009, p.7).

O Turismo Cultural comporta um amplo leque de atuação e atrativos. Para Dias (2006, p.54), a área pode ser dividida em segmentos. No Quadro 1, destacam-se os principais segmentos e atrativos organizados pelo autor:

Quadro 1. Turismo Cultural segundo três segmentações e seus respectivos atrativos.

\begin{tabular}{|c|c|}
\hline SEGMENTAÇÃO & ATRATIVO \\
\hline Turismo Histórico & $\begin{array}{l}\text { Um dos segmentos mais desenvolvidos do turismo } \\
\text { cultural, que compreende as visitas as cidade históricas, } \\
\text { museus, monumentos de valor histórico, entre outros; }\end{array}$ \\
\hline Turismo Étnico & $\begin{array}{l}\text { Segmento dedicado a levar as pessoas a conhecerem } \\
\text { comunidades culturais diferenciadas da cultura mais geral; }\end{array}$ \\
\hline Turismo Gastronômico & $\begin{array}{l}\text { Segmento dedicado à visitação de locais que apresentem } \\
\text { comidas e bebidas típicas da região visitada. }\end{array}$ \\
\hline
\end{tabular}

Fonte: Adaptado de Dias (2006, p.54).

O Turismo Cultural contempla diversos públicos, e públicos específicos demandam a contratação de pessoas qualificadas e especializadas naquele segmento para oferecer um serviço direcionado e com boa qualidade.

\subsection{GASTRONOMIA E TURISMO}

A gastronomia é a união de todos os elementos que envolvem o alimento, como a sua forma de preparo e as técnicas utilizadas. Dessa forma fica visível o vínculo da gastronomia com a cultura: "A gastronomia é um dos elementos mais significativos de uma comunidade, sendo reflexos da cultura, dos usos, costumes e saberes de um local" apontam Sacramento e Silva (2009, p.3). 
Vinculados com a cultura, a gastronomia e o turismo são elementos que andam juntos e não podem ser separados, uma vez que todos que viajam têm a necessidade de consumir e

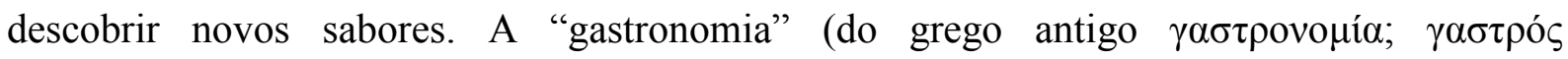
["estômago"] e vouía ["lei"/"conhecimento"]) é um ramo que abrange a culinária, as bebidas, os materiais usados na alimentação e, em geral, todos os aspectos culturais a ela associados" (Rodrigues, 2008, p.311).

São por esses atrativos culturais que os turistas vêm em busca de destinos contrastantes aos seus costumes cotidianos. Essa ideia é reforçada por Fagliari (2005, p.41): "O turista procura sempre conhecer aquilo que lhe é peculiar, diferente de seu cotidiano. Assim, o valor de um atrativo turístico aumenta quando maior sua peculiaridade.” É com esse público interessado na gastronomia que surge um dos segmentos do turismo que se denomina turismo gastronômico. Esse desenvolvimento se dá pela renda que o turismo gastronômico pode trazer para uma comunidade e para todos envolvidos isso fica claro quando:

verifica-se que o Turismo Gastronômico pode trazer uma série de benefícios para todos os envolvidos. No que tange ao destino que o desenvolve, pode incrementar sua oferta turística, diferenciá-lo em relação aos seus concorrentes diretos e indiretos e, ainda, complementar a oferta de lazer e de entretenimento gerando empregos diretos e também aumentando a atratividade de uma localidade, incentivando, por consequência, o aumento da permanência dos visitantes (Gimenes, 2009, p.22).

Um desses diferenciais seria a comercialização de pratos típicos regionais, onde a experiência de desfrutar tanto da hospitalidade local e culinária juntos, somente é possível naquele determinado lugar onde o prato típico é servido, destacando-se em relação aos concorrentes. Essa também é uma forma de gerar renda para os comerciantes envolvidos com este segmento.

O Turismo gastronômico no RN envaidece-se pela sua rica identidade cultural, em parte explicada pelo contraste da cultura sertaneja, onde ocorre a criação de animais de pequeno porte como cabras e galinhas de Angola, em relação à gastronomia à base de camarão e frutos do mar no litoral. Condições naturais diversas produziram riquezas e tradições culinárias distintas e saborosas. De acordo com Dantas (2015):

Os alimentos aquáticos como peixes, crustáceos e moluscos eram tradicionalmente consumidos pelos potiguares do litoral. Já a cultura sertaneja do gado proporciona aos habitantes do sertão seco o consumo de carne bovina. Para os sertanejos o peixe era considerado comida d"água e mais vale "água de carne" do que "carne d"água" (Dantas, 2015, p.24) 


\subsection{HIGIENE NA COMERCIALIZAÇÃO DE ALIMENTOS}

Nos dias atuais observa-se que a população está cada vez mais se alimentando fora de suas casas por motivos diversos. Seja devido ao trabalho ou estudo em tempo integral, ou outros motivos como tempo gasto com deslocamento no trânsito entre casa-trabalho ou casauniversidade. Com o desenvolvimento desse novo perfil de público, houve o crescimento dos comércios de alimentação. Isso é observado no dia a dia seja com o aumento dos restaurantes e bares, seja com o aumento dos alimentos vendidos ao ar livre. Com o avanço dessa demanda, cresce também a comercialização de produtos sem as mínimas condições de controle ou fiscalização, e essa deficiência (ou falta de cuidados) da higienização tanto no preparo quanto na manipulação dos alimentos vem acarretando a sua contaminação e pode transmitir doenças para os consumidores.

No momento em que essa contaminação ocorre com os turistas, consequências negativas são trazidas para o local ou destino turístico, a região e chega a abranger até o país, em que o fato ocorreu. Após um ou repetidos casos de intoxicação alimentar, as pessoas ficam com receio de se alimentar neste local, havendo assim, prejuízo para os turistas e para o estabelecimento, pois os turistas deixarão de frequentar o estabelecimento e, tampouco recomendarão a outros clientes, ao contrário, sempre que possível farão o que é chamado de antipropaganda. Eventos dessa natureza afetam particularmente os destinos no início do seu desenvolvimento como atrativo turístico.

A vigilância sanitária surge com o objetivo de garantir os padrões de segurança e higiene para a sociedade não só nos casos de bares e restaurantes, mas em tudo que possa prejudicar a saúde da sociedade. Dessa forma, foi elaborada a Lei n. 8.080 de 19 de setembro de 1990 (Brasil, 1990):

$\S 1^{\circ}$ Entende-se por vigilância sanitária um conjunto de ações capaz de eliminar, diminuir ou prevenir riscos à saúde e de intervir nos problemas sanitários decorrentes do meio ambiente, da produção e circulação de bens e da prestação de serviços de interesse da saúde, abrangendo: I - o controle de bens de consumo que, direta ou indiretamente, se relacionem com a saúde, compreendidas todas as etapas e processos, da produção ao consumo; e II - o controle da prestação de serviços que se relacionam direta ou indiretamente com a saúde (artigo $6^{\circ}$ parágrafo $\left.1^{\circ}\right)$.

A Agencia Nacional de Vigilância Sanitária [ANVISA] foi criada pela Lei No 9.782 , de 26 de janeiro de 1999 (Brasil, 1999). Ela é uma agência reguladora, vinculada ao Ministério da Saúde, com o campo de atuação em todos os setores relacionados com a saúde 
da população brasileira e sua competência abrange tanto a regulação sanitária quanto a regulação da economia do mercado. Com o propósito de informar às pessoas envolvidas com a comercialização dos alimentos como proceder em relação à higienização, preparação, armazenamento e comercialização, uma cartilha sobre boas práticas para o serviço de alimentação foi elaborada, em conformidade com a Resolução-RDC no 216/2004. (ANVISA, 2004) Essa resolução traz todas as informações referentes à manipulação do alimento desde a edificação, as instalações, os equipamentos, os utensílios até a higienização, manejo de resíduos, preparação dos alimentos, abastecimento de água, armazenamento e transporte do alimento preparado. Com base na cartilha, o local de trabalho deve ter as condições mínimas para a manipulação de alimentos, tanto na limpeza quanto na infraestrutura. Essa cartilha de boas maneiras da ANVISA traz a possibilidade de informar, orientar e tentar qualificar todos os envolvidos com a produção, preparação e distribuição dos alimentos e é uma ótima base tanto para quem está no início de suas atividades gastronômicas quanto àqueles que já estão atuando no mercado há muito tempo.

\section{METODOLOGIA}

Trata-se de um estudo transversal de natureza quantitativa, cujos dados foram coletados de acordo com a livre demanda de clientela que frequentou o estabelecimento no período de 28 de maio a 09 de junho. Devido à dificuldade de abordagens devido ao ruído e aglomerado de pessoas foram obtidas 31 entrevistas semi-estruturadas. Devido à dinâmica do comércio optou-se pela aplicação de formulário estruturado para facilitar o registro das respostas.

Precedendo à elaboração do instrumento, foi realizada uma observação participante. A observação participante permitiu a interação do pesquisador com o espaço social da pesquisa, com a finalidade de compreender o contexto. De acordo com Minayo (2009, p.70), a filosofia fundamental da observação participante é a necessidade que todo pesquisador social tem de relativizar o espaço social de onde provém, aprendendo a se colocar no lugar do outro.

Para caracterizar a hospitalidade no Mercado Público como Atrativo Turístico, o instrumento abrangia questões sobre os seguintes aspectos: (1) o perfil do usuário, (2) característica do mercado e (3) do prato consumido. Os dados foram coletados através de entrevista, utilizando-se de um formulário semiestruturado, aplicado individualmente por meio de entrevista realizada pelo próprio pesquisador. 
Para o tratamento e análise dos dados, as respostas foram transferidas para uma planilha de dados, facilitando a categorização de variáveis. A análise dos resultados também foi norteada pela observação participante do pesquisador no local. Para interpretação dos dados elaborou-se tabelas de frequências e gráficos de contingência favoreceu a análise descritiva:

\begin{abstract}
A pesquisa descritiva, em geral, procura descrever fenômenos ou estabelecer relações entre variáveis. Utiliza técnicas padronizadas de coletas de dados, como o questionário e a observação sistemática. A forma mais comum de apresentação é o levantamento, normalmente realizado mediante questionário e que oferece descrição da situação no momento da pesquisa (Dencker, 1998, p.151).
\end{abstract}

A coleta de dados realizada mediante o Termo de Consentimento, elaborado de acordo com a resolução CNS 466/12 do Conselho Nacional de Saúde-Ministério da Saúde (Brasil, 2012), que foi lido e assinado pelo entrevistado, por se tratar de pesquisa envolvendo seres humanos.

\title{
4. ANÁLISE E DISCUSSÃO DOS RESULTADOS
}

\subsection{PERFIL DE USUÁRIOS DO MERCADO DA REDINHA}

Os consumidores que frequentaram o Mercado Público da Redinha no período da coleta de dados eram, na sua maioria, moradores da cidade de Natal, do sexo masculino, adultos, com escolaridade predominantemente até o $2^{\circ}$ grau.

Observou-se ainda que, os homens que frequentam o Mercado, o utilizam para praticar a comensalidade em forma de bar, com os amigos para beber, comer e conversar. Apesar da maioria do público ser masculino, observou-se também que há utilização do Mercado por parte de famílias compostas por adultos e crianças, que fazem uso da praia como forma de lazer e depois se dirigem ao mercado para se alimentar.

Tabela 1. Perfil dos usuários do Mercado da Redinha. Natal, 2014

\begin{tabular}{|c|c|c|}
\hline & $\mathrm{N}=31$ & $\%$ \\
\hline \multicolumn{3}{|l|}{ Sexo } \\
\hline Masculino & 20 & 65 \\
\hline Feminino & 11 & 35 \\
\hline \multicolumn{3}{|l|}{ Idade } \\
\hline Até 25 anos & 8 & 26 \\
\hline Acima 25 anos & 23 & 74 \\
\hline \multicolumn{3}{|l|}{ Escolaridade } \\
\hline Até $2^{\circ}$ grau & 27 & 87 \\
\hline Acima $2^{\circ}$ grau & 4 & 13 \\
\hline \multicolumn{3}{|l|}{ Origem } \\
\hline Natal & 27 & 87 \\
\hline Outros & 4 & 13 \\
\hline
\end{tabular}


Fonte: Banco de dados da Pesquisa de Lima, (2014).

\subsection{CARACTERIZAÇÃO DO MERCADO}

Logo no início da aplicação dos questionários, quando indagados sobre a „Opinião Geral $^{\text {lee }}$ do Mercado da Redinha (Fig. 7B), todos os participantes, sem exceção, deram opiniões favoráveis ao mercado. Dentre esse total, mais de $80 \%$ dos entrevistados achavam „bom e e 16\% (cinco pessoas) consideraram „ótimo ${ }^{\text {ee }}$, mostrando que o mercado público é bem aceito entre seus clientes. E apesar de nenhum dos participantes ter emitido uma opinião negativa para esse quesito, muitos fizeram ressalvas em relação às melhorias que poderiam ser realizadas no Mercado Público (Fig. 1A), o que já pode ser motivo de preocupação para o atrativo turístico.

Figura 1. (A) Opinião de usuários, (B) Frequência dos usuários ao Mercado da Redinha em Natal, 2014 (n=31)

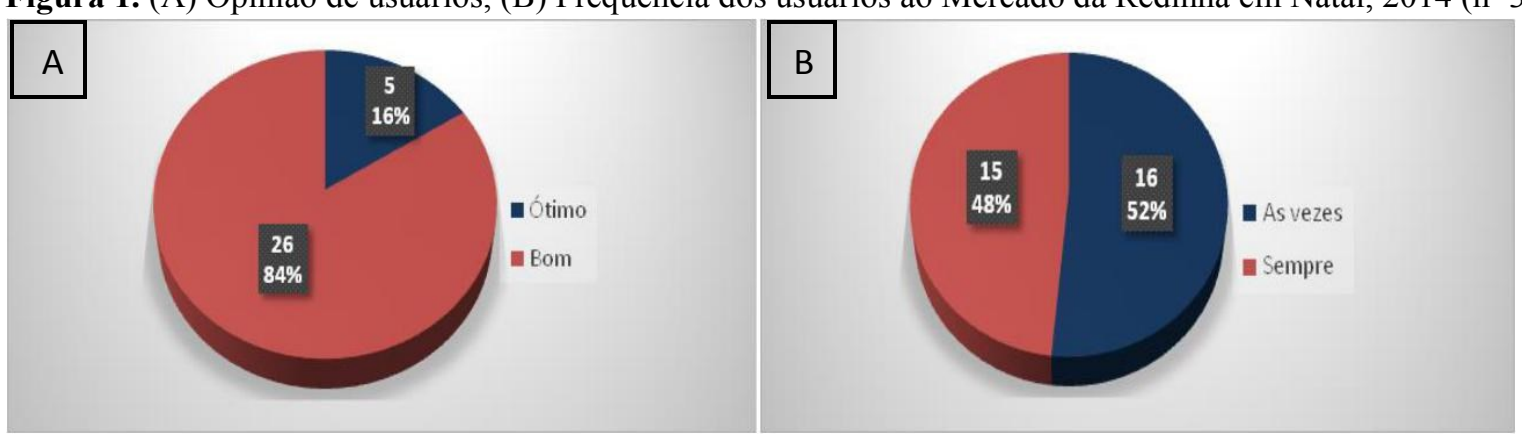

Fonte: Banco de dados da Pesquisa de Lima, (2014).

Os resultados para a „Opinião Geral em relação ao Mercado ${ }^{e e}$ foram bom e ótimo, mas alguns problemas observados pelos usuários foram levantados, especialmente os relacionados à infraestrutura e, algumas sugestões de como poderiam ser realizadas também foram dadas. As soluções visando melhorias no Mercado são de suma importância para impulsionar o desenvolvimento do Turismo, e esse fato é primordial para atrair maior público. Sendo o Mercado da Redinha um mercado municipal, o próprio Município de Natal tem a responsabilidade de melhorias - desde a manutenção na estrutura do prédio e atenção ao saneamento, quanto à acessibilidade de portadores de necessidades especiais, por exemplo.

De acordo com Dias (2013, p.139) "o turismo é profundamente dependente do setor público, de tal forma que podemos colocá-los como imprescindível e principal responsável pela qualidade do produto turístico". Principalmente tratando o turismo como uma das principais atividades econômicas do nosso Estado. 
Sendo assim o poder público - seja ele municipal ou estadual, tem sua parcela de responsabilidade sobre qualquer produto turístico. No caso do Mercado da Redinha, o Município tem essa responsabilidade. Quando o poder público fica ausente e não se responsabiliza por uma manutenção periódica, o bem público tende a se deteriorar (problema mais acentuado ainda em regiões praieiras) o que pode gerar insatisfação dos frequentadores e consequentemente, a redução da demanda de visitantes em longo prazo. Por se tratar de um estabelecimento de Alimentos e Bebidas, a ANVISA (2004) dispõe da Resolução-RDC N ${ }^{\circ}$ 216, de 15 de Setembro de 2004. Essa legislação tem como objetivo, "estabelecer procedimentos de boas práticas para serviços de alimentação a fim de garantir boas condições higiênico-sanitárias do alimento preparado" (ANVISA, 2004, p.2).

Quando perguntado aos usuários do Mercado da Redinha sobre sua frequência de visitas ao estabelecimento, a amostra esteve bastante homogênea: pouco mais da metade afirmou frequentar o mercado esporadicamente e a outra metade afirmou que sempre ia ao Mercado (Figura 1B), utilizando-se do espaço assiduamente. Este perfil proporciona maior credibilidade às outras categorias avaliadas, considerando o ponto de vista de consumidores frequentes e não de pessoas que não estiveram no mercado antes. Todos eram moradores locais, ou seja, não foram encontrados dentre os entrevistados, turistas ou visitantes que estavam no mercado pela primeira vez. A frequência mais significativa foi a do público masculino, e apesar da amostra incluir também alguns casais, jovens até 25 anos e famílias, teve como perfil um público adulto, com mais de 25 anos.

Figura 2. (A) Fonte de conhecimento do Mercado Público da Redinha, (B) Indicação do Mercado da Redinha para outras pessoas, 2014.

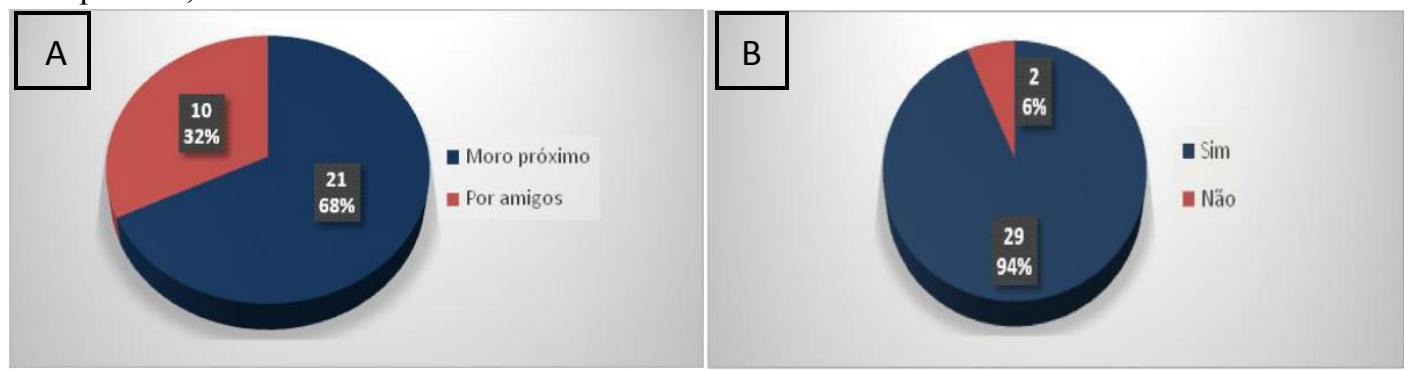

Fonte: Banco de dados da Pesquisa de Lima, (2014).

Em relação à forma de divulgação do Mercado, vinte e um entrevistados representando quase $70 \%$ dos frequentadores, tiveram conhecimento do Mercado por morar próximo às suas instalações, e quase $30 \%$ das pessoas ficaram sabendo da ginga com tapioca por meio da indicação de amigos (Figura 2A). Dessa forma, todos os entrevistados ficaram sabendo através de amigos ou por morar na região. Uma vez que nenhum dos visitantes entrevistados ficou sabendo da existência do mercado e da ginga com tapioca por meio de 
divulgação publicitária, a ausência de visitantes de outras regiões pode ser, em parte, explicada pela ausência de propaganda, com propósito turístico, através dos meios de comunicação.

No momento que se questionou sobre „Indicação ${ }^{e e}$ a grande maioria disse que sim, que indicaria o Mercado Público da Redinha a amigos e conhecidos para o lazer e à alimentação (Fig. 2B). Somente 6\% dos entrevistados não o indicaria a outros. A maioria dos entrevistados fez ressalvas sobre a necessidade de melhorias no estabelecimento, assim como ocorreu com os resultados da primeira pergunta do questionário, quando indagados sobre a avaliação geral do mercado, e as respostas foram "boa" e "ótima" não havendo registros de desaprovação. Ou seja, tanto entre o grupo que não indicaria quanto entre aqueles que indicariam o mercado a outros, todos coincidem sobre a necessidade de melhoria no Mercado, reiterando a satisfação dos clientes em ter o mercado como opção de lazer, alimentação e de sociabilidade com os amigos e reconhecendo, ao mesmo tempo, a insatisfação em conviver sob infraestrutura interna do Mercado Público da Redinha.

A ginga com tapioca é um atrativo tão forte que quando se fala no Mercado da Redinha, faz-se uma associação imediata com o prato, sendo uma das mais combinações de sabores mais representativas da identidade cultural regional. O processo de oficialização da ginga com tapioca como patrimônio imaterial da capital potiguar pode fortalecer o reconhecimento cultural para além dos visitantes locais. Enquanto não houver investimento público efetivo, o Mercado segue desconhecido para muitos que vem à cidade de Natal. Investir em publicidade e atrair novos clientes também significa aumento na indicação por meio de divulgação pessoal do Mercado e da ginga a outros.

A divulgação informal é a principal fonte de informações dos consumidores brasileiros sobre produtos e serviços, segundo estudo realizado em 2010, sobre o comportamento do consumidor (Consultoria Accenture, 2010). No Brasil, 85\% dos consumidores afirmaram ter contato com produtos e serviços por meio de pessoas conhecidas e $66 \%$ consideram essas informações importantes para sua decisão de compra. A propaganda informal no Brasil ganhou uma dimensão amplificada com o advento das mídias sociais. Segundo essa mesma pesquisa, $89 \%$ dos brasileiros frequentemente navegam na internet para procurar informações sobre empresas e suas ofertas. Ser comunicativo é uma característica do brasileiro, e faz parte de seu perfil gostar de trocar experiências com outras pessoas. Nesse sentido, uma propaganda vinculada aos meios de comunicação ou em locais de busca de informações sobre roteiros turísticos. A divulgação seria um fator primordial para tornar o estabelecimento conhecido e 
para incentivar o turismo cultural com a valorização de práticas tradicionais e de pratos típicos expressivos da identidade gastronômica de Natal.

Entre as melhorias sugeridas além da infraestrutura, muitos clientes apontaram para a necessidade de investimento na higiene do local e assepsia do pessoal (Figura 3A) que ocorre, em parte, devido ao abastecimento inconstante de água. A falta de saneamento compromete a qualidade do ambiente e consequentemente afeta a higiene na manipulação e consumo de alimentos e pode expor os usuários às infecções alimentares. Um ambiente fora dos padrões de higiene tem consequências bastante negativas para a imagem turística de uma localidade, considerando que os turistas são os consumidores mais vulneráveis em relação à infecção gastrointestinal de origem alimentar. "Os viajantes necessitam de conselhos sobre alimentos seguros e não seguros em uma região particular. Se a região tiver reputação de alimentos não seguros, a renda proveniente do turismo pode ser afetada" Organização Mundial da Saúde [OMS] (2002, p.80).

Figura 3. (A) Aspectos que demandam melhorias no Mercado da Redinha, (B) Opinião sobre o acesso ao Mercado Público da Redinha, Natal, 2014

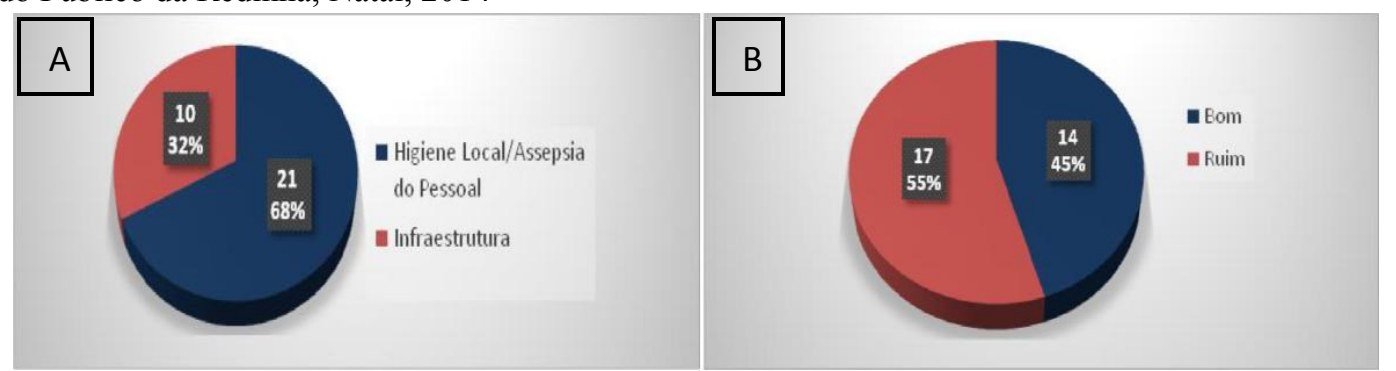

Fonte: Banco de dados da Pesquisa de Lima, (2014).

As sugestões de melhorias em higiene relatadas pelos entrevistados incluíram a limpeza dos sanitários; a limpeza e arrumação dos boxes; fardamento dos funcionários (cozinheiros e garçons) e retirada dos gatos. A adequação dos espaços físicos do Mercado foi o segundo ponto mais apontado e abrangeram desde a reforma e ampliação dos sanitários masculinos e femininos; qualificação de funcionários; implantação de chuveiro para os usuários; melhorias na segurança; ampliação do estacionamento e solucionar o problema da falta de abastecimento de água. Nesse caso, qualquer estabelecimento que tenha interesse de aumentar o seu público principalmente com o turismo deve primar, além de outras coisas, pela higiene do seu estabelecimento. A fácil identificação dos funcionários por meio de uniforme adequado beneficiaria o atendimento no local, reduzindo o tempo de espera. Estabelecimento com atendentes uniformizados expressa a ideia de qualidade em hospitalidade e segurança alimentar. 
Notavelmente, a grande quantidade de gatos no local à espreita dos restos de alimentos e em torno das mesas onde os clientes estão se alimentando constitui outro inconveniente apontado pelos entrevistados. A reprodução dos gatos é um risco à saúde e, cabe inferir que, embora não seja o objeto deste estudo, a proliferação de gatos não é um problema exclusivo do Mercado Público da Redinha, consta como um problema de saúde pública da cidade de Natal como um todo.

Ainda em relação às melhorias no atendimento: conforme citado anteriormente, o principal veículo de comunicação dos brasileiros é a divulgação informal e o segundo canal de informações mais significativo, no Brasil, são as explicações prestadas pelos atendentes nos estabelecimentos comerciais. Resultados de pesquisas anteriores mostram que $72 \%$ dos brasileiros conheceram produtos e serviços a partir de orientações dos atendentes e $51 \%$ se basearam no atendimento prestado para efetuar suas compras (Consultoria Accenture, 2010), reafirmando a importância de qualificação de pessoal e um bom atendimento por parte dos funcionários.

Ao considerar melhorias de infraestrutura, outro aspecto investigado foi a acessibilidade ao Mercado. Praticamente metade da amostra respondeu que sente dificuldade para chegar até o local, classificando o acesso como ruim. Para $45 \%$ dos entrevistados, no entanto, o acesso é bom (Figura 3B). A falta de sinalização foi apontada como o principal problema referente ao acesso. A sinalização é fundamental para toda e qualquer cidade ou ponto turístico que tenha interesse em receber ampla visitação.

\subsection{CARACTERÍSTICA DO PRATO}

Em relação ao cardápio oferecido, observou-se que o tipo de petisco mais consumido pelos clientes no Mercado Público da Redinha é a ginga com tapioca. 32 \% consumiram apenas ginga com tapioca e $42 \%$ pediram ginga mais bebidas e $26 \%$ dos clientes consumiram outros peixes e bebidas. As bebidas escolhidas como acompanhamento foram refrigerante, café, leite, suco ou bebida alcoólica (Fig. 4A). 
Figura 4. (A) Tipos de petisco mais consumidos pelos usuários do Mercado da Redinha, (B) Dinâmica de relações sociais no Mercado da Redinha em Natal, 2014.
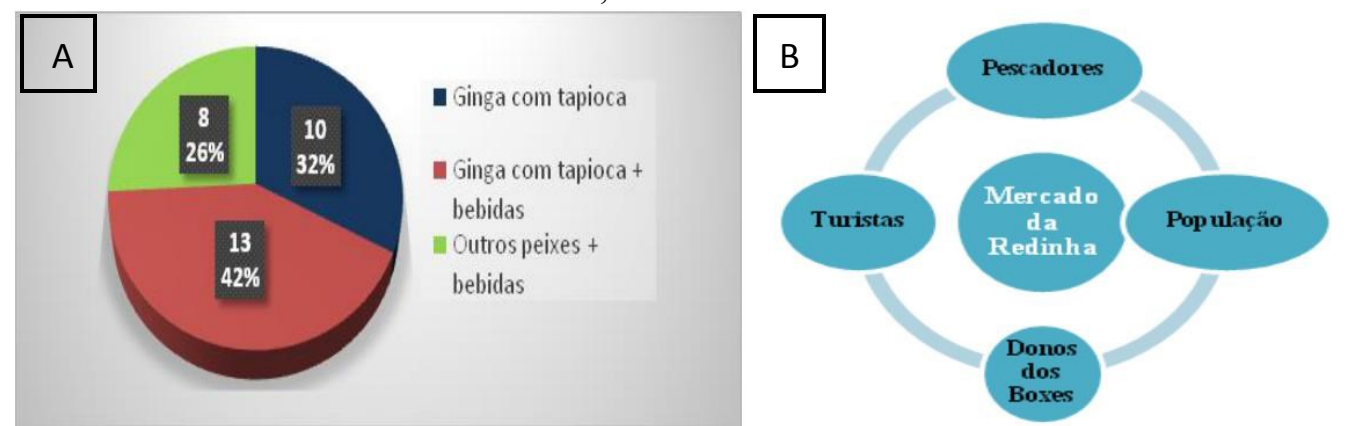

Fonte: Banco de dados da Pesquisa de Lima, (2014).

O peixe miúdo ou as iscas de peixe é a base dos alimentos servidos, uma vez que este Mercado Público se encontra instalado na praia da Redinha, local onde a pesca é uma ocupação bastante tradicional. Outros petiscos incluem porções de carne de sol com macaxeira, camarão no alho e óleo e porções de batata frita. Mas a ginga com tapioca é de longe o petisco mais consumido, somando $74 \%$ do consumo em relação aos outros tipos de peixes. Além da pesca como trabalho, muitos dos pescadores também residem na localidade; e o Mercado da Redinha tem uma grande importância na economia do bairro e também para a economia de cidade. Dessa forma, existe uma relação dinâmica entre os diversos públicos que de alguma maneira usufruem do Mercado (Figura 4B). Os pescadores da ginga a retiram do mar e a vendem para os donos dos boxes. As cozinheiras preparam a ginga artesanalmente antes de fritar, e após o preparo, são vendidas para os turistas e consumidores locais que, por sua vez, utilizam o mercado para alimentação e lazer. E dessa maneira, direta ou indiretamente, todos os envolvidos se beneficiam do bom funcionamento do mercado.

O gosto e a apresentação do petisco são bastante relevantes no momento de decidir onde comer. Em encontros com amigos no Mercado, gosto e apresentação influenciam na escolha do cardápio e motiva a indicação informal do estabelecimento a outros. O sabor dos pratos servidos no Mercado da Redinha foi avaliado de maneira positiva por todos os consumidores entrevistados; quase $70 \%$ definiram o gosto como „bom ee e mais de $30 \%$ relataram que o gosto é ,ótimo ou excelente ${ }^{e e}$. A apresentação do prato servido tem impacto sobre a aceitação, com maior frequência de venda e consumo da ginga com tapioca, das bebidas que o acompanham. A comensalidade em torno da ginga influencia no tempo de permanência gasto no mercado; influi também na indicação do estabelecimento a outros.

Sobre a apresentação do prato, quase $90 \%$ dos clientes acham „boa ${ }^{\text {ee }}$ e $13 \%$ acham „ótima a a forma como o prato é servido no Mercado Municipal de Redinha (Fig. 5A e 5B). A forma simples de como é servida a ginga com tapioca é o que mais chamou a atenção. $\mathrm{Na}$ 
opinião dos clientes, foi essa maneira de colocar a ginga no palito de coqueiro - no lugar do espeto de madeira comumente usado no churrasquinho, o que deu uma característica bastante artesanal ao prato, tornando-o único, exclusivo.

Figura 5. (A) Gosto do prato típico "ginga com tapioca", (B) Aspecto do petisco servido no Mercado da Redinha.

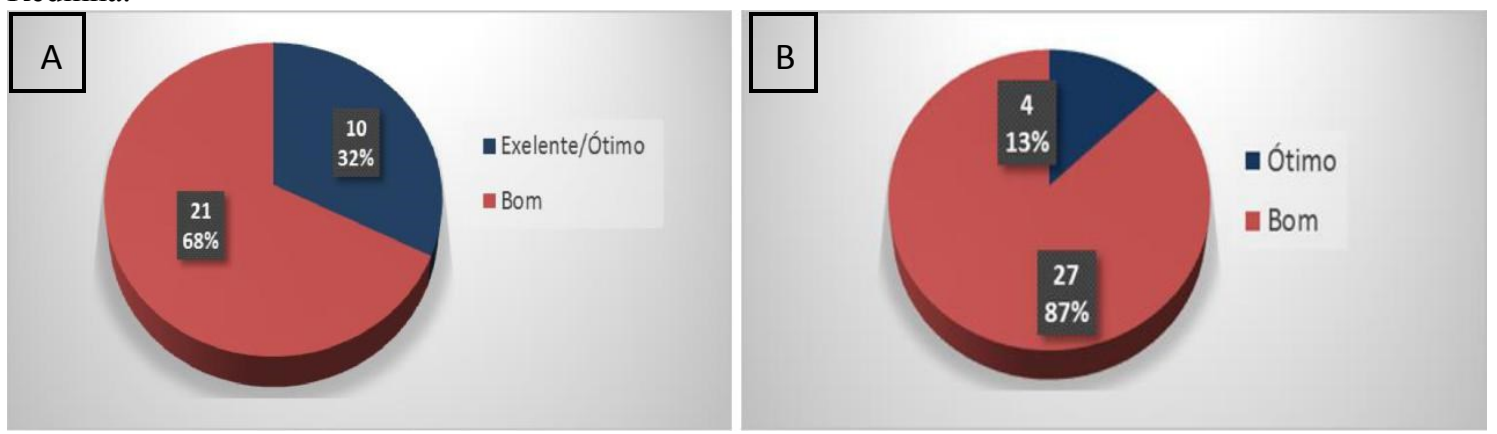

Fonte: Banco de dados da Pesquisa de Lima, (2014).

A boa avaliação dos usuários em relação ao gosto e apresentação do prato foi um dos aspectos positivos mais relevantes no estudo. Comparamos lado a lado os resultados de bom gosto/apresentação do petisco (bom e excelente) mais a opinião geral do mercado (boa e ótima), e confrontamos com as solicitações de melhorias na infraestrutura. Talvez haja realmente uma relação entre ,achar o mercado bom/ótimo ${ }^{\text {ee }}$, com o ,gosto e a apresentação do prato $^{\text {ee }}$ Vale lembrar que, quando foram questionados sobre "opinião geral do mercado", a pergunta introdutória do estudo, $100 \%$ dos usuários ,acha o mercado bom/ótimo ee muitos destacaram as melhorias que achavam importantes que fossem realizadas, especialmente na estrutura do prédio. Ao avaliarmos especificamente ,demandas de melhorias na infraestrutura $^{e e}$, os usuários apontaram a necessidade de adequação do espaço em relação à qualidade do ambiente. Contudo, a boa apreciação no consumo do petisco tradicional do mercado parece compensar as exigências de melhorias na infraestrutura e talvez as companhias comensais mascarem o contexto inadequado do local e as urgências de reformas principalmente no espaço interno. A ginga com tapioca se configurou como um importante atrativo gastronômico para a comensalidade local e supre de certa forma, o contexto inadequado para consumo de alimentos.

A frequente aprovação do público pelo ,gosto e apresentação do prato ${ }^{\text {ee }}$ pode ser explicada, ainda, pelo simples fato da farinha de mandioca e do peixe fazerem parte da tradição alimentar do brasileiro, especialmente na região nordeste. Esses hábitos estão incluídos na dieta brasileira antes mesmo da colonização, pois fazia parte da alimentação indígena. Os índios que viviam aqui consumiam a farinha de mandioca, peixes, camarão, frutas e caças. Quase tudo que se comia era adicionado de farinha como complemento ao peixe seco, às sopas e aos caldos. A farinha aparecia na alimentação dentro dos navios que 
transportavam escravos como forma de sustentá-lo até chegar ao seu destino. Além disso, a farinha de mandioca também fazia parte da vida do sertanejo (Cascudo 2011).

Figura 6. (A) Opinião sobre o custo do prato típico "ginga com tapioca" no Mercado Público Municipal; (B) Qualidade do serviço no Mercado da Redinha, Natal, 2014.

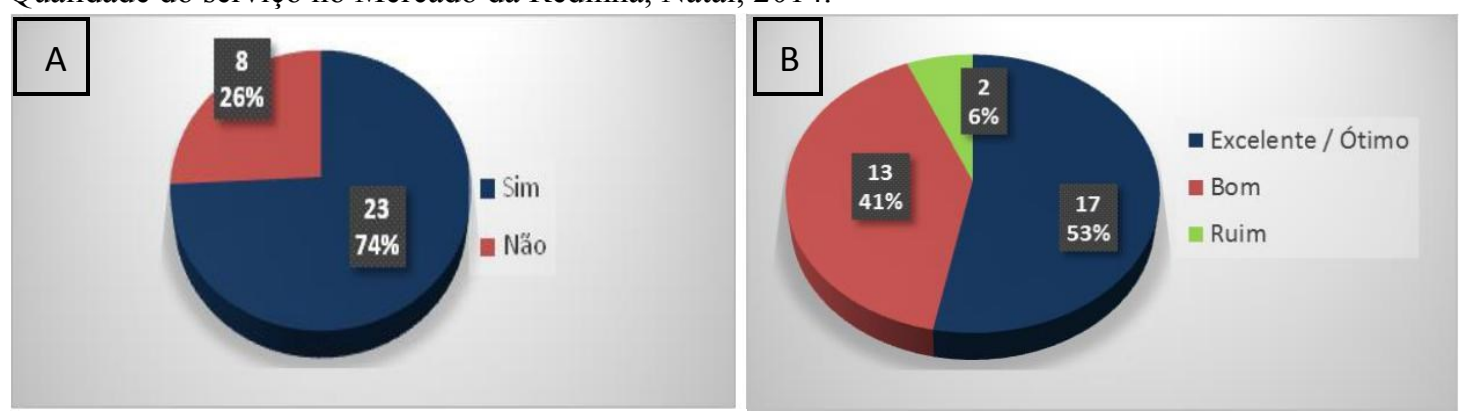

Fonte: Banco de dados da Pesquisa de Lima, (2014).

Além do custo acessível, a qualidade do atendimento é fundamental para o desenvolvimento do serviço e do comércio. Os resultados para o „custo do petisco ie informam que mais de $70 \%$ dos participantes acharam justo o preço cobrado, e $26 \%$ dos clientes não consideraram o valor cobrado justo. No entanto, quando comparamos esses resultados com a quantidade de visitas ao mercado, metade dos entrevistados respondeu que vão ,sempre e e outra metade frequenta ,às vezes ${ }^{\text {ee }}$, verificamos que o preço parece não afetar a regularidade de ida ao mercado.

E nas opiniões sobre as melhorias necessárias, o preço do petisco não esteve entre os fatores sugeridos. Cabe inferir que o grupo de consumidores partilha de saberes do senso comum e, portanto, nos resultados podem expressar contradições, ambiguidades por refletir, muitas vezes, opiniões imediatistas.

Em relação à qualidade do atendimento prestado pelos funcionários do Mercado, 53\% dos clientes consideraram excelente ou ótimo, $41 \%$ disseram que o atendimento é bom e $6 \%$ relataram que o atendimento é ruim (Fig. 7B). A hospitalidade evidenciada no atendimento foi o aspecto que mais gerou satisfação por parte dos usuários. "O atendimento é a forma como nos relacionamos com os clientes" (Marques, 2006, p.39). O ato de receber bem é um atributo que todos os comerciantes deveriam cultivar. De acordo com Castelli (2010, p.4) a "hospitalidade significa receber, abrigar, alimentar e cuidar do visitante." A hospitalidade é primordial para todos que têm interesse em interagir com o público, pois se trata de uma ferramenta cotidiana importante para surpreender cordialmente os turistas. Admitindo a hospitalidade como um propósito em turismo, melhorias na infraestrutura para além da pintura de fachada, com investimento público direcionado em controle de qualidade higiênico-sanitário; incorporação do espaço em roteiro cultural e promoção do espaço na mídia são etapas prioritárias de melhorias. Contudo, a ótima frequência de consumo do prato 
devido à perfeita combinação de sabores, além da recente oficialização da ginga com tapioca como patrimônio imaterial regional são aspectos favoráveis à expansão do turismo gastronômico em Natal.

Figura 7. (A) Ginga com tapioca. Mercado da Redinha. Natal, 2014. (B) Mercado público da Redinha.

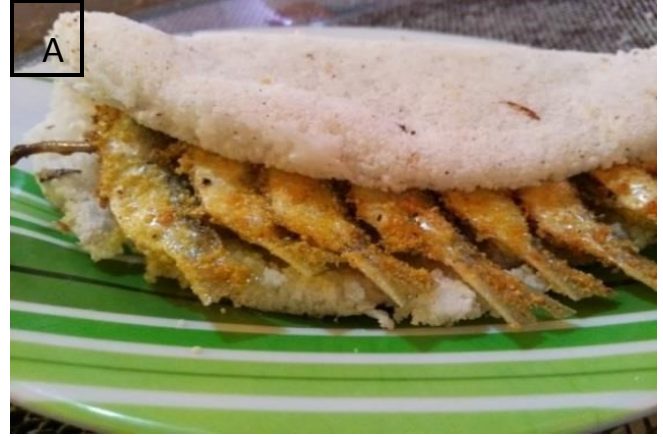

Fonte: Regis ( 2014)

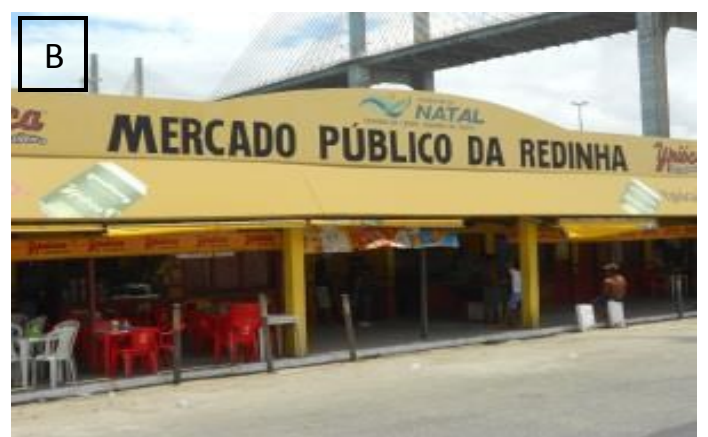

Fonte: Carvalho ( 2015)

\section{CONSIDERAÇÕES FINAIS}

A gastronomia assegura condições sócio-vitais para consumidores locais e turistas. $\mathrm{O}$ Turismo Gastronômico favorece o desenvolvimento regional motivando o turismo cultural e a visitação de processos artesanais de comidas e bebidas regionais. O serviço gastronômico de boa qualidade é responsável pela fidelização e indicação do destino a outros usuários. Turistas vinculam o gosto apreciado ao local visitado.

Reconhecer a identidade gastronômica contribui para a elaboração de roteiros gastronômicos. Este estudo mostrou que a hospitalidade é afetada pelos aspectos improvisados da infraestrutura e a criação de roteiro gastronômico potiguar que inclua o Mercado da Redinha, depende de estratégias de hospitalidade e melhoria da qualidade do serviço para assegurar um nível de qualidade surpreendente.

Embora a cultura transcenda a corrente higienista, é desejável que consumidor local e ou turista tenha segurança alimentar. Insatisfações de ordem higiênico-sanitária do estabelecimento foram as queixas mais frequentes. Os usuários atribuem essa situação precária à falta de investimento no local por parte do poder público. Melhorias na infraestrutura relacionadas ao saneamento básico; qualificação de pessoal em segurança alimentar; a inclusão do Mercado nos Roteiros e nas sinalizações da cidade são medidas desejáveis. Investimentos na qualidade do serviço e na infraestrutura interna podem assegurar o potencial turístico do Mercado. 
A ginga com tapioca é o prato mais valorizado e responsável pela fidelização dos usuários do Mercado Público da Redinha. A valorização se deve ao bom atendimento, gosto ideal e boa apresentação do prato, principalmente, pelo público masculino.

Tendo em vista a recente oficialização da ginga com tapioca como Patrimônio Imaterial Regional, estudos qualitativos por meio de etnografias e observação participante poderão contribuir para aprofundar questões relacionadas à história de vida e a trajetória da receita regional. Também faz sentido um estudo sobre publicidade/divulgação e avaliação da gestão pública de recursos destinados à revitalização de espaços tradicionais e preservação da memória social.

\section{REFERÊNCIAS}

Agência Nacional de Vigilância Sanitária (2004). Cartilha sobre as boas práticas para serviços de alimentação. Brasília: Anvisa.

Agencia Nacional de Vigilância Sanitária (2004). Resolução $R D C n^{\circ} 216$, de 15 de setembro de 2004. Brasília: Anvisa.

Barreto, M. (2003). Manual de iniciação ao estudo do turismo. (13a ed.). Campinas: Papirus.

Brasil.(1990). Lei n. 8.080, de 19 de setembro de (1990): Dispõe sobre as condições para a promoção, proteção e recuperação da saúde, a organização e o funcionamento dos serviços correspondentes e dá outras providências. Brasília: DF. Recuperado em 23 de junho, 2016, de http://www.planalto.gov.br/ccivil_03/leis/L8080.htm.

Brasil (1990). Lei $N^{o}$ 9.782, de 26 de janeiro de 1999: Define o Sistema Nacional de Vigilância Sanitária, cria a Agência Nacional de Vigilância Sanitária, e dá outras providências. Brasília: DF. Recuperado em 23 de junho, 2016, de http://www.planalto.gov.br/ccivil_03/leis/L9782.htm.

Carvalho, J. (2015). Mercado da Redinha, onde surgiu a ginga com tapioca. (fotografia).

Natal, RN. Recuperado em 23 de junho, 2016, de

https://vivernatal.wordpress.com/2015/05/14/5-lugares-com-precos-acessiveis-para-comercomida-regional-em-natal/

Cascudo, L.C. (2011). História da alimentação no Brasil. (4a ed.) São Paulo: Global.

Castelli, G. (2010). Hospitalidade: a inovação na gestão das organizações prestadoras de serviços. São Paulo: Saraiva.

Consultoria Accenture Brasil.(2010). O País no Estudo Global de Comportamento do Consumidor. São Paulo: Gestão Empresarial.

Dantas, R.F., Medeiros M.C., Damasceno K.S.F.S. \& Dantas A.G.A. (2014). Complexidade de sabores e saberes. Apresentado na Reunião Brasileira de Antropologia, Natal, RN, Brasil, 
29.

Dantas, R.F. (2015). Ginga com Tapioca: De Dalila à Ivanize. Das origens à atualidade. Natal: Sebo Vermelho.

Dencker A.F.M. (1998). Metodologia de pesquisa em Turismo. São Paulo: Futura.

Dias, R. (2006). Turismo e Patrimônio Cultural. São Paulo: Saraiva.

Dias, R. (2013). Introdução ao Turismo. São Paulo: Atlas.

Dias, R. \& Aguiar, M.R. (2002). Fundamentos do turismo: conceitos, normas e definições. Campinas, São Paulo: Alínea.

Fagliari, G.S. (2005). Turismo e Alimentação: Análises Introdutórias. São Paulo: Roca.

Gimenes, M. H. S. G. (2009). O uso turístico das comidas tradicionais: algumas reflexões a partir do Barreado, prato típico do litoral paranaense (Brasil). Turismo \& Sociedade, 2 (1), 8-24.

Levi-Strauss, C. (2006). A origem dos modos à mesa. (Coleção Mitológicas, Vol.3). São Paulo: Cosac \&Naify.

Lima, C. O. (2014). O Mercado Público da Redinha como atrativo turístico: o caso da ginga com tapioca. Monografia de graduação em Turismo. Universidade Federal do Rio Grande do Norte- UFRN, Natal, RN, Brasil.

Marques, F. (2006). Guia prático da excelência em serviços: como conquistar clientes, aumentar os lucros e viver melhor. São Paulo: Nobel.

Medeiros, M. C. (2015). Prefácio. In: R.F. Dantas. Ginga com Tapioca: De Dalila à Ivanize. Das origens à atualidade. Natal, RN: Sebo Vermelho.

Minayo, M.C.S. (2009). Trabalho de Campo: Contexto de observação, interação e descoberta. In M.C.S Minayo, S.F., Deslandes, \& R. Gomes. Pesquisa Social: Teoria, método e criatividade. Petrópolis, RJ: Vozes.

Ministério do Turismo (2006). Segmentação do Turismo: Marcos Conceituais. Brasília: Ministério do Turismo.

Ministério do Turismo. (2009). Estudo da Competitividade do Turismo Brasileiro. Brasília: Ministério do Turismo.

Ministério do Turismo (2010). Turismo Cultural: orientações básicas. Brasília: Ministério do Turismo.

Ministério da Saúde (2012). Resolução CNS 466/12 do Conselho Nacional de Saúde. Projetos de pesquisa envolvendo seres humanos deverão atender a esta Resolução. Brasília, DF. Recuperado em 23 de junho, 2016, de http://conselho.saude.gov.br/web_comissoes/conep/index.html. 
Myanaki, J., Leite, E., Cesar, P. A. B. \& Stigliano, B. V. (2007). Cultura e Turismo. São Paulo: Ministério do Turismo.

Panosso Netto, A \& Ansarah, M.G.R. (2009). Segmentação do Mercado Turístico: estudos, produtos e perspectivas. Barueri, SP: Manole.

Peccini, R. (2013). A gastronomia e o turismo. Revista Rosa dos Ventos. 5 (2), 206-217.

Organização Mundial da Saúde, (2002). Segurança Básica dos Alimentos para Profissionais de Saúde. São Paulo: Roca.

Regis A. Fotografia. (2014) In: França T. Imortalizando a ginga com tapioca. Natal: Tribuna do Norte. Recuperando em 23 de junho, 2016, de

http://www.tribunadonorte.com.br/noticia/imortalizando-a-ginga-com-tapioca/278910

Rodrigues, S. G. G. (2008). A contemporaneidade da gastronomia ludovicense: (Cuxá) X Big Mac/Mac Donald na cultura, identidade e tradição. Revista Cambiassú, 4, 311-325.

Sacramento, A.C. \& Silva, R.S. (2009). A Gastronomia nos mercados públicos do Recife. Instrumento de valorização da identidade cultural. Recife: Senac.

Secretaria Municipal de Meio Ambiente e Urbanismo. (2005). Anuário 2005.

Secretaria Municipal de Meio Ambiente e Urbanismo. (2009). Anuário 2009.

Shlüter, R.G. (2003). Gastronomia e Turismo. São Paulo: Aleph.

Woortmann, E.F. (1992). Da complementaridade à dependência: espaço, tempo e gênero em „comunidades pesqueiras' do Nordeste. Revista Brasileira de Ciências Sociais, 18, 41-60. 